\title{
An integrated peer outreach and clinic-based intervention to improve the sexual health of young men who have sex with men in Myanmar: A Link Up evaluation
}

Population Council

Follow this and additional works at: https://knowledgecommons.popcouncil.org/departments_sbsr-hiv

Part of the Demography, Population, and Ecology Commons, Family, Life Course, and Society Commons, Gender and Sexuality Commons, and the International Public Health Commons How does access to this work benefit you? Let us know!

\section{Recommended Citation}

Population Council. 2016. "An integrated peer outreach and clinic-based intervention to improve the sexual health of young men who have sex with men in Myanmar: A Link Up evaluation," Link Up Study Brief. Washington, DC: Population Council. 
In recent years, Myanmar has undergone rapid political and social change that has led to an environment with increased opportunities to fill gaps in HIV programming and research. The prevalence of HIV among the general population in Myanmar is less than 1 percent. $^{1}$ Among men who have sex with men (MSM), the HIV prevalence is significantly higher at 10.4 percent. Since 2011, there has been an increase in the HIV prevalence among MSM, despite decreasing HIV prevalence rates in other key populations including female sex workers and people who inject drugs.

There are currently an estimated 240,000 MSM in Myanmar, corresponding to 1.4 percent of the total adult male population. ${ }^{2}$ Young MSM (under age 25) are a particularly vulnerable subset of this key population, with an HIV infection rate that is nearly five times that of their counterparts in Myanmar. ${ }^{1}$ Therefore, evidence-based programs that focus on reducing the HIV risk of young MSM in Myanmar are warranted.

This brief describes an evaluation that assessed the impact of a peer-driven intervention for young MSM in Myanmar, designed to improve the sexual health and rights of this marginalized community. The intervention and evaluation activities were conducted as part of Link Up, a global consortium led by the International HIV/ AIDS Alliance aimed at improving sexual and reproductive health and rights among young vulnerable communities in Africa and Asia. In collaboration with Burnet Institute, the Population Council-led evaluation study sought to assess whether the Link Up intervention improved sexual and health-seeking behaviors, and whether it reduced perceived stigma by MSM in health care settings. We also examined the barriers and enablers to uptake of HIV and sexual health services.

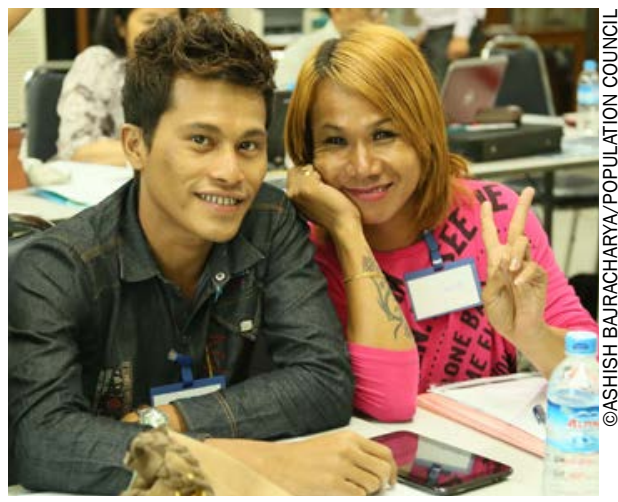

As part of Link Up, the Population Council and Burnet Institue conducted evaluation that assessed the impact of a peer-driven intervention for young MSM in Myanmar, designed to improve the sexual health and rights of this marginalized community.

\section{KEY MESSAGES}

Peer educators played an important role in acting as referral agents and ultimately increasing MSM's health-seeking behaviors.

There was a trend toward increased HIV testing uptake after the Link Up intervention.

Sexual behavior change may require more intensive and longer duration of intervention. 


\section{THE INTERVENTION}

The Link Up intervention was implemented in 10 town-

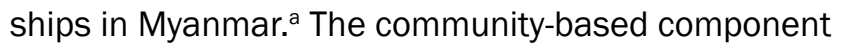
of the intervention included outreach by peer educators (PEs) who were MSM themselves and trained by Alliance Myanmar. PEs were trained in health promotion and supportive counseling with a focus on HIV and sexually transmitted infection (STI) knowledge, gender norms, sexuality, and gender-based violence (GBV). Once trained, they conducted outreach and provided MSM in their community with condoms and lubricants, counseling, and referrals to appropriate services. The clinic-based service package included HIV counseling and testing, STI screening and treatment, psychosocial support, and sexual health counseling. PEs accompanied MSM to clinics or actively followed up and encouraged completion of referrals. When they completed their referrals and presented their redeemed referral slips to Link Up-affiliated community-based organizations (CBOs), participants received a reimbursement of 4,000 Myanmar Kyat (US\$4.00) from the CBO.

The clinic-based component of the intervention was implemented through clinics operated by local Link Up partner, Marie Stopes International Myanmar (MSIM). Staff were trained in child protection, confidentiality, informed choice, and consent, and were sensitized about legal/ethical issues and HIV and STI risk profiles of key populations, including MSM. Safer sex counseling was integrated with HIV and STI testing and treatment. Youth- and MSM-friendly environments were created through refurbishments of existing sites and the establishment of new sites. Additionally, clinics offered lubricants and commodities to MSM free of charge. Referrals were provided for specialized services including antiretroviral therapy, post-violence care, cancer care, and psychosocial and harm reduction counseling.

\section{STUDY METHODOLOGY}

In order to assess whether the Link Up intervention had an effect on the behaviors and practices of MSM,

aThe 10 townships include Dawei, Mawlamyaing, Thingungyun, Pathein, Bago, Pyay, Myingyan, Chanmyathars, Pyiguitagun, and Monywa.

bUS1.00 = 1,000 Myanmar Kyats (MMK) as of January 2014

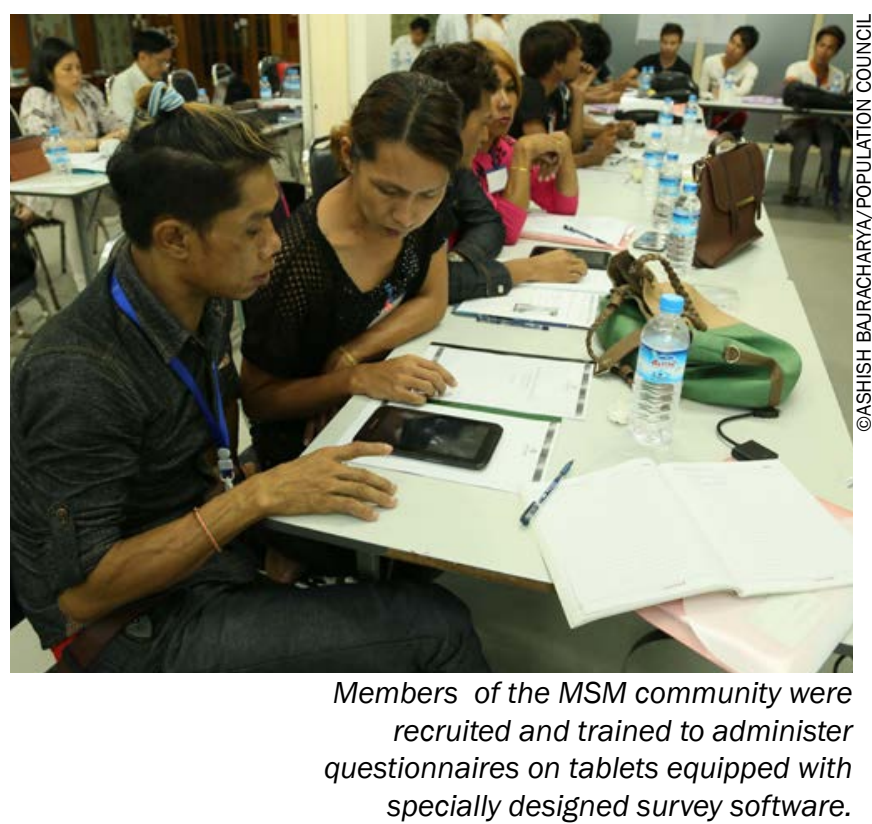

a robust evaluation was designed using multiple data collection activities. A quantitative survey was administered among young members of the MSM community (ages 18 to $24^{c}$ ) prior to the intervention (October 2015) and six months after the intervention began (April 2016). We conducted the surveys in townships with Link Up activities (intervention townships) and without Link Up activities (comparison townships). Respondent-driven sampling (RDS), which involved incentive-based peer referrals, was used to recruit survey participants. Additionally, health facility assessments and an audit of completed service referrals were conducted. Mystery clients were used to assess the quality of health services in intervention facilities. Lastly, focus group discussions and in-depth interviews were conducted in intervention townships with participating CBOs, service providers, and MSM who had at least one contact with the Link Up intervention in order to gain an understanding of their perceptions of and experiences with the intervention package. Fifty-four MSM took part in focus groups after the six-month intervention. Of those, 19 identified as apwint, seven identified as apone, and 25 identified as tha-nge. ${ }^{d}$

'The intervention was targeted at young MSM ages 15 to 24 years; however, the research component was conducted among those 18 to 24 years of age.

${ }^{\mathrm{d} A p o n e}$ (hidden, receptive); apwint (open, receptive); tha-nge (masculine, insertive). See Different Needs for Different Sexual Identities for explanation of the sexual identities. 
Additionally, 9 service providers from MSIM, 11 staff from CBOs, and 18 PEs were interviewed.

The intervention was implemented in 10 townships, of which three were purposively selected for the evaluation (Pathein, Mawlamyine, and Bago). Three comparable townships where no intervention was planned were selected as comparison townships (Kalay, Magwe, Thanlyin). Comparison townships were selected based on the size of the government hospital (100 beds and above), population size (above 250,000), presence of an MSIM clinic similar to the intervention sites, and the presence of a large outreach HIV prevention program for key populations similar to the intervention sites. Each study site was the capital of its state or region.

\section{SURVEY STUDY POPULATION}

Sociodemographic and sexual behavior characteristics of the study population at baseline and endline are presented in Table 1. The mean age of participants at baseline and endline was approximately 20 years in both the intervention and comparison groups. There were some significant differences in the sociodemographic and sexual behavioral characteristics of MSM in the intervention versus the comparison group at baseline (forced sex with first male partner) as well as at endline (education, sexual debut age, forced sex with first male partner). Most participants classified themselves as single, with a small proportion having ever been married to a woman, and some having been married to (or currently living with) a man. In all four

TABLE 1 PROPORTION OF MSM WHO ARE HIV NEGATIVE OR UNKNOWN STATUS WHO ACCESSED A HIV TEST IN THE PAST 3 MONTHS

\begin{tabular}{|c|c|c|c|c|c|c|}
\hline & \multicolumn{2}{|c|}{$\begin{array}{l}\text { Intervention } \\
\text { townships }\end{array}$} & \multicolumn{2}{|c|}{$\begin{array}{l}\text { Comparison } \\
\text { townships }\end{array}$} & \multirow[b]{2}{*}{$\begin{array}{l}\text { p-value* } \\
\text { A vs C }\end{array}$} & \multirow[b]{2}{*}{$\begin{array}{l}\text { p-value* } \\
\text { B vs D }\end{array}$} \\
\hline & $\begin{array}{c}\text { Baseline } \\
(\mathrm{n}=314) \\
\% \\
\mathrm{~A}\end{array}$ & $\begin{array}{c}\text { Endline } \\
(\mathrm{n}=267) \\
\% \\
\mathrm{~B}\end{array}$ & $\begin{array}{l}\text { Baseline } \\
(\mathrm{n}=309) \\
\quad \% \\
\mathrm{C}\end{array}$ & $\begin{array}{l}\text { Endline } \\
(\mathrm{n}=318) \\
\% \\
\mathrm{D}\end{array}$ & & \\
\hline Age, mean years (SD) & $20.4(2.1)$ & $20.9(2.0)$ & $20.4(1.7)$ & $20.6(1.9)$ & 0.78 & 0.20 \\
\hline $\begin{array}{l}\text { Education, highest level completed } \\
\text { Primary or lower } \\
\text { Middle or high school } \\
\text { University of graduated }\end{array}$ & $\begin{array}{l}12 \\
77 \\
11\end{array}$ & $\begin{array}{l}13 \\
74 \\
13\end{array}$ & $\begin{array}{r}7 \\
78 \\
15\end{array}$ & $\begin{array}{r}6 \\
68 \\
26\end{array}$ & 0.12 & 0.019 \\
\hline $\begin{array}{l}\text { Marital status } \\
\text { Never married } \\
\text { Currently married to a woman } \\
\text { Committed to a man as married } \\
\text { Formally married to a man or woman }\end{array}$ & $\begin{array}{r}82 \\
6 \\
7 \\
5\end{array}$ & $\begin{array}{r}80 \\
5 \\
14 \\
1\end{array}$ & $\begin{array}{r}82 \\
1 \\
12 \\
5\end{array}$ & $\begin{array}{r}87 \\
3 \\
10 \\
<1\end{array}$ & 0.20 & 0.20 \\
\hline $\begin{array}{l}\text { Sexual identity } \\
\text { Apone (hidden, receptive) } \\
\text { Apwint (open, receptive) } \\
\text { Tha-nge (masculine, insertive) }\end{array}$ & $\begin{array}{l}11 \\
33 \\
56\end{array}$ & $\begin{array}{l}11 \\
39 \\
50\end{array}$ & $\begin{array}{l}21 \\
26 \\
53\end{array}$ & $\begin{array}{l}15 \\
21 \\
64\end{array}$ & 0.28 & 0.073 \\
\hline \multicolumn{7}{|l|}{ Sexual behavior characteristics } \\
\hline $\begin{array}{l}\text { Age at sexual debut with male partner, } \\
\text { mean years (SD), } n=566\end{array}$ & $16.7(2.5)$ & $16.1(2.9)$ & $16.8(2.2)$ & $17.0(2.6)$ & 0.84 & 0.009 \\
\hline $\begin{array}{l}\text { Forced or coerced into first sexual experi- } \\
\text { ence with a male partner }\end{array}$ & 21 & 13 & 9 & 22 & 0.007 & 0.047 \\
\hline Had sexual intercourse in the last 90 days & 90 & 96 & 95 & 91 & 0.073 & 0.20 \\
\hline Male sex partners only & 71 & 89 & 77 & 82 & 0.072 & 0.23 \\
\hline Female sex partners only & 11 & 1 & 2 & 2 & & \\
\hline Both male \& female partners & 18 & 10 & 21 & 16 & & \\
\hline
\end{tabular}

*Omnibus $p$-values taken from chi-square tests of independence for categorical variables, and between-group t-tests for continuous variables. 


\section{Different needs for different sexual identities}

Participants identified as "tha-nge" (hidden MSM, insertive partner [hidden/i]), "apone" (hidden MSM, receptive partner [hidden/r]), and "apwint" (open MSM, typically receptive [open/r]). Open/r were more likely to report STI symptoms in the last 12 months, ever being tested for HIV, and having accessed an MSMfriendly drop-in center or been reached by a PE. Hidden/i were the least likely to disclose their male-male sexual behavior to service providers. Overall, hidden MSM accessed services the least. Interventions should consider the unique differences between these different identity types. ${ }^{3}$

The clinic place is nice, good ventilation, but it's small and over crowded with women and girls. Thus most of the MSM don't want to go to the clinic, especially the hidden type of MSM. They don't want to meet with many people....

-MSM participant

samples, tha-nge (masculine) MSM accounted for approximately one-half of all participants enrolled at both baseline and endline (varying from 50 to 64 percent), and the proportion of apwint (open type) varied from 20 to 39 percent. Over one-third of participants had a current regular sex partner. The majority (90 percent) had had sexual intercourse in the last 90 days; more than 70 percent in all four samples reported having sex only with male partners.

\section{Intervention coverage}

Coverage of the intervention was relatively low, with only one-third of participants reporting exposure to the Link Up intervention at endline. ${ }^{\mathrm{e}}$

\section{Uptake of HIV testing and counseling and sexual health services}

There was an increase in the proportion of those in intervention townships who had received an HIV test in the past three months from baseline to endline; however, this increase was not statistically significant (Figure 1).

There was also a slight increase in those who visited a clinic for health information from baseline to endline

${ }^{\mathrm{e}}$ Coverage may have been low because the intervention had only been occurring for six months before endline data were collected. The coverage rate may be somewhat underestimated due to the use of non-branded shirts and hats by staff (i.e., MSM may not have known they were exposed to Link Up PEs). (intervention townships baseline vs. endline: 71 percent vs. 81 percent; comparison townships baseline vs. endline: 58 percent vs. 61 percent; $p$-value $=0.15$ ). The increase in comparison townships is to some extent to be expected, since there are other interventions

FIGURE 1 PROPORTION OF HIV NEGATIVE OR UNKNOWN STATUS MSM WHO ACCESSED A HIV TEST IN THE PAST 3 MONTHS

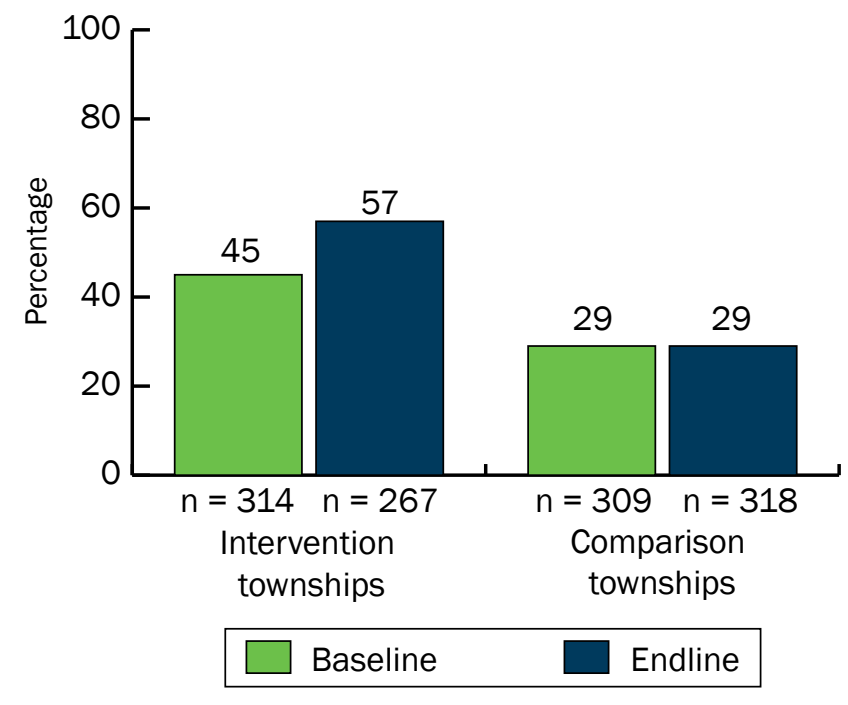

p-value $=0.35$ *

* $p$-value for the intervention by time interaction from multi-level regression modeling adjusting for ethnicity, marital status, main occupation, sexual identity, level of MSM status disclosure, and having multiple or casual partners. 
and national initiatives on HIV in Myanmar that may have influenced these outcomes.

\section{Sexual behaviors}

In intervention townships, there was a decrease in the percentage of MSM who reported unprotected anal sex in the past 30 days with regular male partners and paying male clients from baseline to endline (41 percent vs. 37 percent and 25 percent vs. 14 percent, respectively) (Figures 2 and 3). These increases, however, were not statistically significantly different from the observed changes in comparison townships ( $p$-value $=0.95$ and $p$-value $=0.15$, respectively .

\section{Stigma and discrimination}

The Link Up intervention was relatively successful at sensitizing service providers on respectful MSM treatment and care, but not to a level of statistical significance. The proportion of MSM who had been refused access to health services was reduced in intervention townships and comparison townships, but there was a

FIGURE 2 PROPORTION OF MSM WITH ONE OR MORE UNPROTECTED ANAL SEX ACTS WITH REGULAR MALE PARTNERS IN THE PAST 30 DAYS

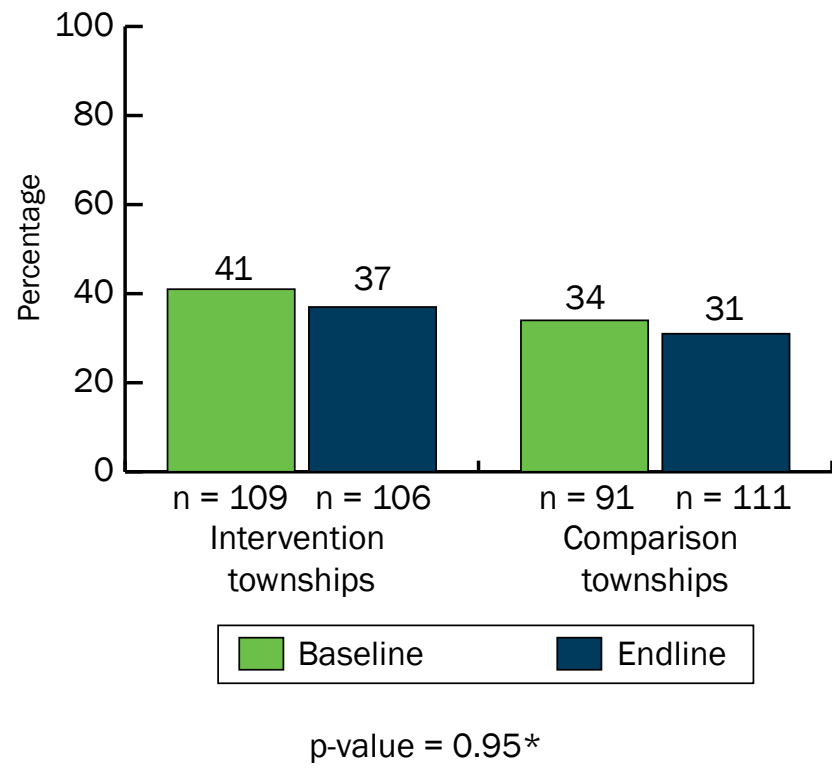

\footnotetext{
* $p$-value for the intervention by time interaction from multi-level regression modeling, accounting for seed clustering but otherwise not adjusted for potential covariates.
}

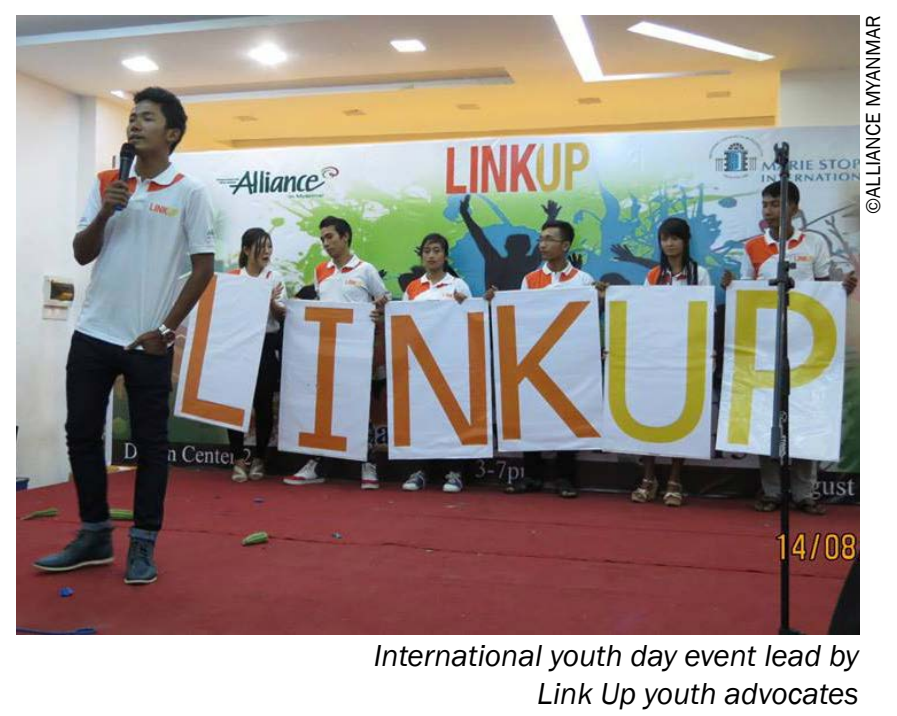

greater change in intervention townships (intervention baseline vs. endline: 4 percent vs. $<1$ percent; comparison baseline vs. endline: $<1$ percent vs. 0.0 percent).

\section{FIGURE 3 PROPORTION OF MSM WITH ONE OR MORE UNPROTECTED ANAL SEX ACTS WITH PAYING MALE CLIENTS IN THE PAST 30 DAYS}

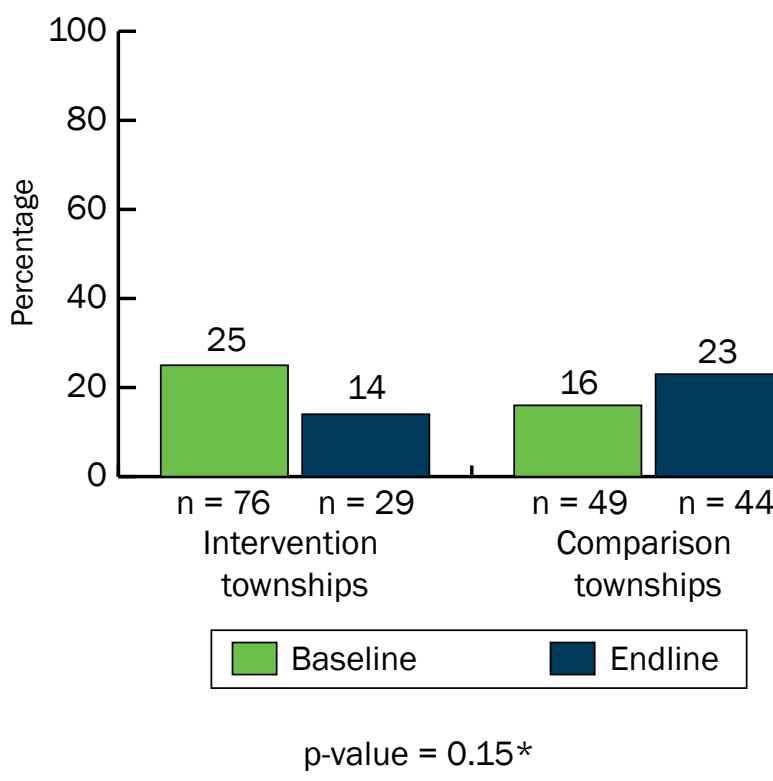

* $p$-value for the intervention by time interaction from multi-level regression modeling, accounting for seed clustering but otherwise not adjusted for potential covariates. 
The proportion of participants who disclosed their MSM status to a service provider was high at baseline and remained high at endline in both intervention and comparison townships. This is likely due to the fact that a fairly high proportion MSM reported using MSMfriendly drop-in centers in the past 12 months in both intervention (over 70 percent) and comparison townships (over 50 percent) (Figure 4).

A small proportion in both intervention and comparison groups indicated they experienced stigmatizing attitudes from health care providers at baseline as well as endline (less than 5 percent). Again, this may likely be due to MSM accessing services through nongovernmental organizations as opposed to mainstream services.

However, qualitative interviews indicated that MSM still experience stigma in Myanmar-in the community and in government health facilities. A change in societal and social norms may be needed before MSM can be fully accepted at health services, particularly in mainstream health services.

FIGURE 4 PROPORTION DISCLOSING MSM STATUS TO COUNSELOR DURING HIV SERVICE

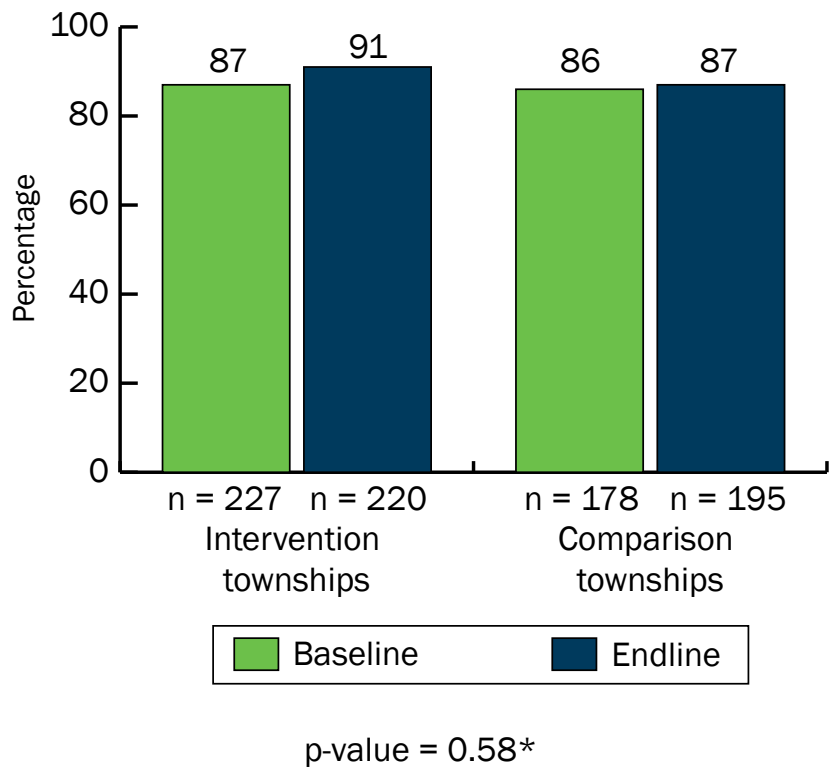

* $\mathrm{p}$-value for the intervention by time interaction from multi-level regression modeling, accounting for seed clustering but otherwise not adjusted for potential covariates. ...if I were tested and positive result is

found, I'm afraid of my partner knowing.

The community may also stay away from

me....

-MSM participant

...I like going to INGO clinic. The staffs

from Government clinic have a bad atti-

tude toward us, being MSM, they some-

times shout at us and discriminate. Thus

I don't wanna go there....

-MSM participant

\section{Service access}

According to service statistics, there was an increase in the mean number of MSM clients receiving both HIV and STI testing services. In the 12 months before baseline data collection, $28 \mathrm{MSM}$ had received both services, compared to 107 in the 12 months before endline. Likewise, in the month before baseline, just one MSM had received both services, compared to 10 MSM in the month preceding endline (Figure 5).

FIGURE 5 MEAN NUMBER OF MSM CLIENTS RECEIVING BOTH HIV AND STI TESTING SERVICES

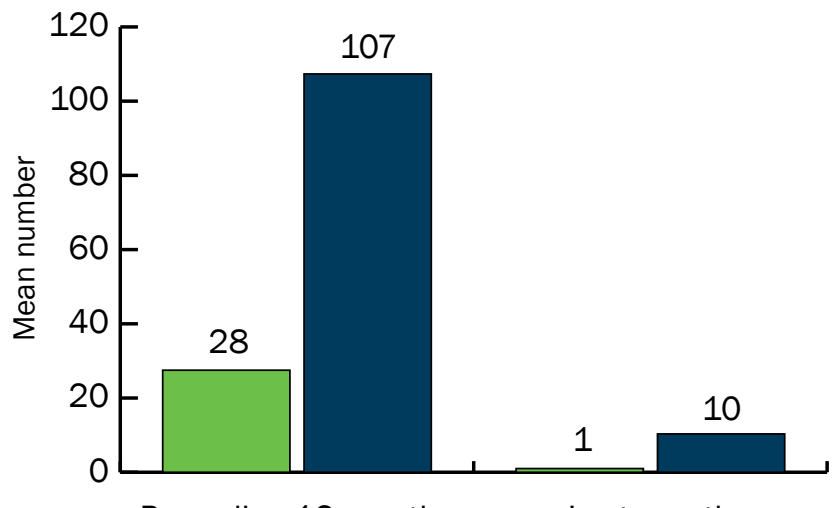

Preceding 12 months Last month

Baseline

Endline

6 An integrated peer outreach and clinic-based intervention to improve the sexual health of young MSM in Myanmar 


\section{Myanmar Youth Stars: Building Youth Capacity to Fight Stigma and Discrimination}

Myanmar Youth Stars (MYS) is the most visible network of young people that involves all key populations in Myanmar, including young MSM, young people who inject drugs (PWID), and young female sex workers (FSWs). The Link Up program implemented activities with MYS to strengthen their capacity to fight stigma and discrimination against young people who are at an elevated risk of HIV. Link Up and other projects enabled MYS to actively engage in training and advocacy efforts, and to gain wider recognition among young key populations and stakeholders in Myanmar.

The Population Council, in partnership with Myanmar Partners in Policy and Research (MPPR), conducted a participatory capacity assessment to document the Link Up Project's effects on MYS's advocacy capacity and external policy engagement (March-August 2015). This assessment found unique strengths in MYS's enthusiastic and energetic membership and their ability to reach and advocate for all young key populations across the country. The assessment also identified the need for organizational capacity building, improved inclusiveness programming to represent all MYS communitiess' interests, and the need for sustainable funding sources as well as strategic partnerships with other CBOs working with young key populations.

\section{MSM's perceptions of the intervention}

Participants reported an appreciation for the interactions among PEs and the MSM community in the intervention townships. Overall, they reported satisfaction with the peer-led sexual health activities, including the HIV testing services.

...we usually meet each other [referring

to PEs] during night time, at the time of

looking for our partners.... If we are in-

terested in blood test, PE accompanied

us to the clinic, that's the point I like

most...feeling we are not alone.....

-MSM participant

...if we don't understand something

during the discussion or health talk, we

can ask them questions as they are also

MSM, same with us! If we ask them a

question, they explained us patiently.

-MSM participant

\section{IMPLICATIONS AND DISCUSSION}

This is the first rigorous evaluation of an integrated community and clinic-based intervention targeting young MSM. After only six months of the Link Up intervention-and despite limited coverage-there were trends towards improvements among MSM in accessing HIV testing services. While there were no significant positive changes in sexual behaviors, this may be partially explained by the short intervention time period. Furthermore, prior studies have shown that peer education programs are more likely to improve knowledge and change health-seeking behaviors rather than change sexual behaviors. ${ }^{4}$ Both the quantitative and qualitative findings of this evaluation support that PEs played an important role in acting as referral agents and ultimately increasing MSM's healthseeking behaviors.

High-quality services are of immense importance to vulnerable populations, but linking these populations to services is arguably even more important. Although this evaluation did not find significant changes in HIV testing rates or reductions in sexual risk behaviors, qualitative findings suggest that linkages to community and clinic services are being formed as part of the Link Up intervention. Because MSM are often a hidden and stigmatized population in Myanmar, programs for MSM should strengthen linkages formed through PEs along 
with MSM-friendly services in order to ensure that HIVpositive MSM receive proper care and treatment, and HIV-negative MSM are able to stay negative. Because PEs are often trusted and influential members of the community, working through PEs could have Ionger-term lasting behavioral changes in the community beyond the program.

Taken together, these findings suggest that the Link Up project was successful at integrating peer outreach and clinic-based components, and building capacity of clinics to provide MSM-friendly services. We would expect the results to be even more substantial if measured after a longer period of time and similarly sustained interventions.

\section{REFRENCES}

1. National AIDS Programme. 2014. "Global AIDS response progress report: Myanmar.” Nay Pyi Daw, Myanmar: Ministry of Health.

2. - . 2012. "HIV sentinel sero-surveillance survey report, 2012." Naypyidaw, Myanmar: Ministry of Health.

3. Tun, W. et al. 2016. "Does sexual identity matter in accessing services?: Risk profile and health-seeking behaviors of different sexual identity types of young men who have sex with men in Myanmar." Accepted for presentation at 21st International AIDS Conference (AIDS 2016), Durban, South Africa, 18-22 July.

4. Chandra-Mouli, Venkatraman, Catherine Lane and Sylvia Wong. 2015. "What does not work in adolescent sexual and reproductive health: A review of evidence on interventions commonly accepted as best practices," Global Health Science and Practice 3(3): 333-340.

\section{LINKUP}

Link Up aims to improve the sexual and reproductive health and rights (SRHR) of one million young people affected by HIV across five countries in Africa and Asia. The project is being implemented by a consortium of partners led by the International HIV/AIDS Alliance.

\section{For more information, visit www.link-up.org}

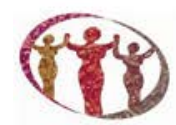

ATHENA

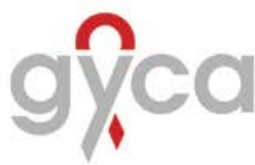

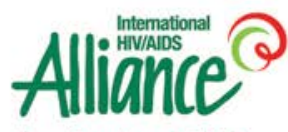

Together to end AIDS

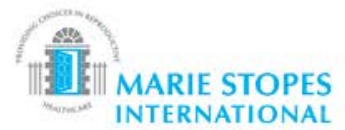

INTERNATIONAL

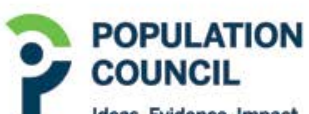

Ideas. Evidence. Impact.
STOP

AIDS

NOW!

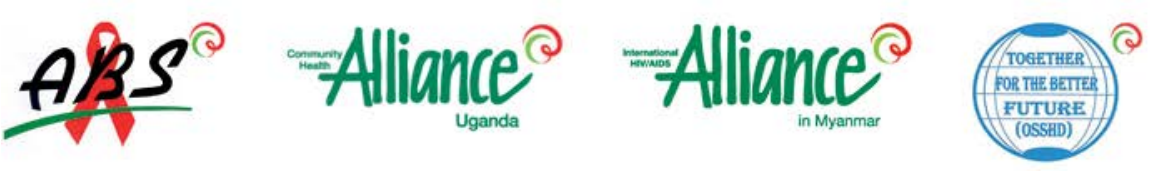

(1)

Government of the Netherlands Funded by the Ministry of Foreign Affairs of the government of the Netherlands.

POPULATION COUNCIL

Ideas. Evidence. Impact.
The Population Council confronts critical health and development issues-from stopping the spread of HIV to improving reproductive health and ensuring that young people lead full and productive lives. Through biomedical, social science and public health research in about 50 countries, the Council works with our partners to deliver solutions that lead to more effective policies, programs, and technologies to improve lives worldwide. Established in 1952 and headquartered in New York, the Council is a nongovernmental, nonprofit organization with an international board of trustees.

Suggested citation: Population Council. 2016. "An integrated peer outreach and clinic-based intervention to improve the sexual health of young men who have sex with men in Myanmar: a Link Up evaluation," Link Up Study Brief. Washington, DC: Population Council.

www.popcouncil.org

(c) 2016 The Population Council, Inc. 